\title{
Selective Electrochemical Conversion of Biomass-derived Valeric Acid to Ethers/Esters
}

\author{
Yuchen liu ${ }^{l}$, Gang Yuan ${ }^{1}$, Xiaona Ren ${ }^{1}$ and Qingfa Wang ${ }^{1,2, *}$ \\ ${ }^{1}$ Key Laboratory for Green Chemical Technology of the Ministry of Education, School of Chemical \\ Engineering and Technology, Tianjin University, Tianjin 300072, P. R. China \\ ${ }^{2}$ Collaborative Innovation Centre of Chemical Science and Engineering (Tianjin), Tianjin University, \\ Tianjin 300072, P. R. China \\ *E-mail: qfwang@tju.edu.cn
}

doi: $10.20964 / 2018.04 .43$

Received: 29 December 2017 / Accepted: 13 February 2018 / Published: 6 March 2018

To quantitatively convert biomass into value-added chemicals or biofuels is still a great challenge. Herein, we develop an efficient electrochemical method to convert the biomass-derived valeric acid into ethers (butyl methyl ether and butyraldehyde dimethyl acetal) or esters (methyl valerate) on boron-doped diamond (BDD) electrode in methanol solution. The products distribution was well controlled by tuning the supporting electrolyte and the $\mathrm{KOH}$ amount. $98.7 \%$ selectivity and ca. 58\% Faraday efficiency for ethers and 96\% selectivity for esters were achieved by optimizing the supporting electrolytes, initial molar ratio of VA to $\mathrm{KOH}$, VA feed concentration and anodic potential. Strong alkali as supporting electrolyte, high VA feed concentration and initial VA/KOH=1 (mol/mol) favoured the formation of ether products. Fatty acid methyl esters were high-selectively (>96\%) produced by using $\mathrm{NaClO}_{4}$ as the supporting electrolyte and/or adding excessive $\mathrm{KOH}$ (initial $\mathrm{KOH} / \mathrm{VA}$ ratio beyond 2:1). Moreover, partially replacing methanol with ethanol, only one new diether (1,1-diethoxybutane) was formed. A rational mechanism of synthetic butyraldehyde dimethyl acetal via electrocatalytic decarboxylation, rearrangement of carbenium ion, Aldol reaction on BDD in alcohols solution was developed. This strategy may provide a new direction for renewable chemicals and fuels from biomass.

Keywords: Valeric acid; electrochemistry; catalysis; selective conversion

\section{FULL TEXT}

(C) 2018 The Authors. Published by ESG (www.electrochemsci.org). This article is an open access article distributed under the terms and conditions of the Creative Commons Attribution license (http://creativecommons.org/licenses/by/4.0/). 